\title{
ANÁLISIS DE LA INFECCIÓN DE Colletotrichum gloeosporioides (Penz.) Penz. \& Sacc. DE FRUTOS DE AGUACATERO ${ }^{1}$
}

\author{
ÉDGAR SAÚL RODRÍGUEZ-LÓPEZ², ELIZABETH CÁRDENAS-SORIANO, \\ SANJUANA HERNÁNDEZ-DELGADO ${ }^{4}$, ADRIANA GUTIÉRREZ-DIEZ ${ }^{5}$, \\ NETZAHUALCOYOTL MAYEK-PÉREZ ${ }^{6}$
}

RESUMEN - La patogénesis de Colletotrichum gloeosporioides (Penz.) Penz. \& Sacc. del estado de Michoacán, México se caracterizó en frutos de aguacatero (Persea americana L.) cultivar 'Hass'. El hongo causó los síntomas característicos de la enfermedad denominada 'antracnosis' a partir de los diez días después de la inoculación. La tasa de infección del hongo entre tratamientos fue significativamente diferente $(\mathrm{p} \leq 0.05)$ a partir del sexto día de la inoculación y el desarrollo de la enfermedad se explicó por un modelo de regresión lineal simple $(\mathrm{Y}=1.123+0.1133 \mathrm{X})$. No se detectó la formación de apresorios pero sí la síntesis de una capa mucilaginosa asociada con los tubos germinativos. El proceso infectivo del hongo se manifestó con la penetración de las hifas intra e inter-celularmente y con la producción de acérvulos a partir de los 12 días después de la inoculación. Los síntomas de la antracnosis se asociaron con la degradación de polifenoles, plasmólisis, necrosis y desintegración celular

Palabras Clave: Persea americana L., antracnosis, patogenicidad, patogénesis.

\section{ANALYSIS OF Colletotrichum gloeosporioides (Penz.) Penz. \& Sacc. INFECTION OF AVOCADO FRUITS}

\begin{abstract}
The pathogenesis of Colletotrichum gloeosporioides (Penz.) Penz. \& Sacc. from the state of Michoacán, México was characterized in avocado (Persea americana L.) fruits cv. 'Hass'. The fungus caused typical disease symptoms of 'anthracnose' ten days after inoculation. Fungal infection rate was significantly different $(\mathrm{p} \leq 0.05)$ between treatments since the sixth day after inoculation and the disease development was explained by one simple linear regression model $(\mathrm{Y}=1.123+0.1133 \mathrm{X})$. No appresoria were found but one mucilagous layer associated to germ tubes was detected. Fungal infective process started with intra and intercellular penetration by hyphae and after, acervuli were produced twelve days after inoculation. Anthracnose symptoms were associated with poly-phenol degradation, plasmolysis, necrosis and cell disintegration Index terms: Persea americana L., antrhracnose, pathogenicity, pathogenesis.
\end{abstract}

1'(Trabalho 031-13). Recebido em: 03-01-2013. Aceito para publicação em: 06-09-2013.

${ }^{2}$ M. Sc. Centro de Biotecnología Genómica, Instituto Politécnico Nacional. Blvd. del Maestro s/n esq. Elías Piña, Col. Narciso Mendoza, 88710, Reynosa, México. Tel/Fax (+52) 8999243627.E-mail: esrodriguez@ipn.mx

${ }^{3}$ Dr. Sci. Profesor Titular. Instituto de Fitosanidad. Colegio de Posgraduados. Montecillo, México. 56230. E-mail: ecardenas@colpos.mx ${ }^{4}$ M. Sc. CBG-IPN. E-mail: shernandezd@ipn.mx

${ }^{5}$ Dr. Sci. Facultad de Agronomía, UANL. General Escobedo, México. E-mail: mcgudiez@hotmail.com

${ }^{6}$ Dr. Sci. CBG-IPN. E-mail: nmayek@ipn.mx 
El género Colletotrichum es causante de enfermedades prácticamente en todas las cosechas agrícolas del mundo (WHITELAW et al., 2007). Los síntomas típicos de la infección por Colletotrichum se denominan 'antracnosis' que se caracterizan por el hundimiento necrosado del tejido donde se producen masas de conidias dentro de un acérvulo (FREEMAN et al., 2000). La antracnosis se presenta en tejidos de plantas en desarrollo y maduros, afecta frutos durante su desarrollo en el campo así como frutos maduros durante su almacenaje (PRUSKY et al., 2000). En frutos de aguacate, la antracnosis ocasionada por C. gloeosporioides (Penz.) Penz \& Sacc. prevalece durante temporadas lluviosas y humedad relativa alta $(>80 \%)$ (TALHINHAS et al., 2005). El hongo infecta con temperaturas de 20 a $28{ }^{\circ} \mathrm{C}$ (FREEMAN et al., 1996). Las etapas de desarrollo de las especies de Colletotrichum pueden separarse en: 1) deposición en las superficie del hospedante, 2) fijación de la conidia en la superficie, 3 ) germinación de la conidia, 4) producción del apresorio, 5) penetración de la epidermis de la planta, 6) crecimiento y colonización del tejido del hospedante y 7) producción de acérvulos y esporulación (RODRÍGUEZ-LÓPEZ et al., 2009). Las conidias son variables en tamaño y su forma es cilíndrica con puntas redondeadas (CANO et al., 2004). El hongo produce apresorios melanizados con dimensiones variables (de 6 a $20 \times 4$ a $12 \mu \mathrm{m}$ ) a partir del cual se produce una púa de infección que penetra al fruto al degradar la cutícula mediante enzimas degradadoras de la pared celular y presión de turgencia, permaneciendo latente hasta que el fruto madura (BENO; PRUSKY, 2000). En campo, los frutos presentan síntomas denominados 'viruela' y 'clavo'. El síntoma de viruela inicia con manchas pequeñas de color café claro y, posteriormente, café oscuras y hundidas. Con el tiempo la lesión toma un aspecto seco y quebradizo, en forma de cráter, llegando a desprenderse. El síntoma de clavo se manifiesta como lesiones irregulares color café oscuro y hundidas que, en condiciones de humedad relativa elevada, coalescen (ZAMORAMAGDALENO et al., 2001). La antracnosis ocasiona pérdidas sustanciales por el declive de frutos durante el almacenaje y la comercialización (FREEMAN et al., 1996) y se manifiesta con la presencia de manchas circulares café oscuras en el pericarpio y daños por ablandamiento y pudrición del mesocarpio (PRUSKY et al., 2001). En estudios histológicos de la patogénesis realizados en aguacate mostraron un patrón de penetración de Colletotrichum, el tubo germinativo forma un apresorio, después una punta infectiva que penetra la pared periclinal de las células epidérmicas (BENO; PRUSKY, 2000). Los objetivos del presente trabajo fueron determinar el desarrollo de la infección por C. gloeosporiodes en frutos de aguacate var. 'Hass' así como analizar la patogénesis histopatológicamente.

Frutos de aguacate 'Hass' infectados con síntomas de antracnosis se colectaron en huertos de Uruapan, Michoacán durante junio de 2007. De los frutos colectados se cortó la zona donde se observó el síntoma típico de la enfermedad y se realizaron cortes de tejido de una superficie aproximada de 1 $\mathrm{cm}^{2}$. Luego, el tejido se desinfestó con hipoclorito de sodio $1 \%$ durante $30 \mathrm{~s}$. Posteriormente, se colocaron los tejidos en cajas Petri con medio de cultivo Papa - Dextrosa - Agar (PDA) acidificado con ácido láctico, e incubado por 15 días a temperatura ambiente $\left(25\right.$ a $\left.29^{\circ} \mathrm{C}\right)$ (TALHINHAS et al., 2005). Los aislamientos puros se obtuvieron mediante resiembras constantes en PDA de punta de hifa, mientras que para la identificación del hongo se analizaron conidias con base en lo reportado por CANO et al. (2004) y ROCA et al. (2000). La producción de conidias se obtuvo a partir de cultivos monoconidiales, de donde se extrajeron tres discos con sacabocados estéril de $10 \mathrm{~mm}$ de diámetro mismos que se colocaron en $45 \mathrm{~mL}$ de medio líquido V8 al $20 \%$ (CASCINO et al., 1990) y se incubaron en agitación orbital constante de $150 \mathrm{rpm}$ (XIAO et al., 2004) a $25^{\circ} \mathrm{C}$ por cinco días (TALHINHAS et al., 2005). Las conidias se suspendieron en una solución amortiguadora de sodio-fosfato $10 \mathrm{mM}$ (pH 7.2) (PRUSKY et al., 2001) y, posteriormente, se filtraron con gasa estéril para eliminar el micelio y los fragmentos de medio de cultivo. Cuarenta frutos sanos del cultivar Hass se lavaron con jabón y se desinfestaron con hipoclorito de sodio $1.5 \%$ durante $30 \mathrm{~s}$. Posteriormente, se enjuagaron por tres veces con agua destilada (VILLANUEVA et al., 2006) y se secaron por convección libre. Una vez secos, 20 frutos se inocularon con $10 \mu \mathrm{L}$ de la suspensión de conidias $\left(10^{5}\right.$ conidias $\left.\mathrm{mL}^{-1}\right)$ (TALHINHAS et al., 2005) en tres puntos de su eje longitudinal (FREEMAN et al., 1996) al colocar una gota de la suspensión con micropipeta y sin realizar punción o herida. Los otros veinte frutos se inocularon con agua destilada estéril. Los frutos se colocaron en charolas de plástico previamente desinfectadas con alcohol etílico $70 \%$ durante 5 min y se mantuvieron en condiciones de humedad relativa superior al $80 \%$ (PRUSKY et al., 2001) y temperatura de $20^{\circ} \mathrm{C}$ (KIM et al., 1999; PRUSKY et al., 2001) y fotoperiodo de $12 \mathrm{~h} \mathrm{luz} \mathrm{/} \mathrm{oscuridad} \mathrm{(BOD} \mathrm{Incubator} \mathrm{Precision} \mathrm{818,}$ Thermo Fisher, Waltham, MA, EUA) durante 15 días. Cada tres días $(0,3,6,9,12$ y 15 días después de la inoculación) se registró el largo y el ancho de 
lesión (en $\mathrm{mm}$ ) para obtener la superficie aproximada a un círculo con la fórmula área de la lesión $=\pi^{*} \mathrm{r}^{2}$ de los tres puntos de inoculación de cuatro frutos de tomados al azar (doce valores). Una vez medidas las lesiones causadas por la antracnosis, se cortó aproximadamente $1 \mathrm{~cm}^{2}$ del pericarpio y a $5 \mathrm{~mm}$ de profundidad después de la lesión en el mesocarpio. Las muestras se colocaron en frascos con solución fijadora de tejidos FAA (Formaldehído-Ac. acético glacial-Alcohol etílico absoluto-Agua; 100-50-500$350 \mathrm{~mL}$, respectivamente). Las muestras se lavaron tres veces con agua y se escurrieron previo a la infiltración en paraplast ${ }^{\circledR}$ (SIGMA, Chemical Co. St. Louis, EUA) que se llevó a cabo en un procesador automático de tejidos marca TISSUE-TEK II (C.O. Chemical Co. Buffalo, NY, EUA) donde se sumergieron por periodos de $3 \mathrm{~h}$ en soluciones deshidratantes de alcohol etílico al 50\%, $70 \%, 96 \%$ y $100 \%$; mezcla 1:1 alcohol etílico absoluto-xileno; tres cambios en xileno y dos cambios en paraplast ${ }^{\circledR}$. Para la inclusión en paraplast ${ }^{\circledR}$ los tejidos se retiraron del procesador automático, se colocaron en moldes de papel conteniendo paraplast ${ }^{\circledR}$ caliente y se enfriaron. Los bloques de paraplast ${ }^{\circledR}$ conteniendo segmentos de tejido de aproximadamente $1 \mathrm{~cm}^{2}$ se montaron en bases de madera para fijarlos al micrótomo rotatorio American Optical Company (modelo Spencer 820). De cada muestra se hicieron cortes de $10 \mu \mathrm{m}$ de grosor en series, mismos que se pegaron en un portaobjetos y luego se colocaron en un baño de flotación con agua caliente $\mathrm{a} \pm 70{ }^{\circ} \mathrm{C}$ y grenetina. Los cortes se tiñeron por tinción diferencial con safranina-verde rápido (ZAMORA-MAGDALENO et al., 2011). Primero, se eliminó el paraplast ${ }^{\circledR}$ mediante tres cambios de xileno y los tejidos se hidrataron con alcohol etílico $96 \%$, $70 \%$ y $50 \%$ ( 3 min en cada cambio). La tinción con safranina se realizó por $1 \mathrm{~h}$; posteriormente, los cortes se lavaron y deshidrataron en una serie gradual ascendente de alcohol etílico de $50 \%$, $70 \%$ y $96 \%$. Finalmente, se aplicó el colorante verde rápido por uno o dos segundos, se decantó el sobrante y se lavó con alcohol etílico $96 \%$ y tres cambios de xileno. Los cortes se montaron con resina sintética. Las muestras teñidas se observaron al microscopio modelo fotomicroscopio III Carl Zeiss ${ }^{\circledR}$. Con los datos de área de lesión se estimó la media \pm error estándar por cada fecha de muestreo. Los datos de área de lesión entre tratamientos se compararon con la prueba no paramétrica de Mann-Whitney (RAMÍREZ-GUZMÁN y LÓPEZ TIRADO, 1993). Luego, los datos de superficie de lesión se transformaron con el valor de $\log _{10}$ y estos valores se sometieron al análisis de regresión lineal simple. El análisis estadístico se llevó a cabo con el programa
GraphPad Prism versión 6.02 (GraphPad Software $\AA$; La Jolla, EUA). En cuanto a la patogénesis, se registró la aparición de lesiones de las células del mesocarpio, lesiones tempranas, producción de polifenoles, hiperplasia, desorganización celular, células necrosadas, colapsadas y la formación de acérvulos y los cambios a nivel microscópico se registraron con el equipo de miscroscopía descrito.

La patogenicidad de los cultivos monoconidiales de C. gloeosporioides se evaluó en frutos de aguacate en etapa de ' $3 / 4$ de corte', que son frutos que tardan de 15 a 17 días para alcanzar su madurez fisiológica. Lesiones características en el área donde se inoculó el fruto se observaron a partir de los 10 ddi (Figura 1). El crecimiento de la lesión de los 0 a los 15 ddi fue más acelerado a partir de los 12 ddi (Figura 2). La tasa de infección del hongo entre tratamientos fue significativamente diferente $(\mathrm{p} \leq 0.05)$ a partir del sexto día de la inoculación de acuerdo con la prueba de Mann-Whitney. El desarrollo de la antracnosis en frutos de aguacatero se explicó mediante un modelo de regresión lineal simple $\left(\mathrm{Y}=1.123+0.1133 \mathrm{X} ; \mathrm{R}^{2}=0.96\right)^{* *}($ Figura 3$)$. El exocarpio del aguacate está cubierto por una capa de ceras y la cutícula es gruesa y se proyecta hacia las paredes anticlinales de las células epidermales. La epidermis es uniestratificada, sus células contienen polifenoles de color azul, mismos que se encuentran de manera natural en dichas células epidermales (Figura 4-A). Debajo de ésta, se encuentran varios estratos de células parenquimatosas con polifenoles en su interior y limitando este estrato celular del mesocarpio se encuentran grupos de esclereidas o células esclerenquimatosas (Figura 4-B). El mesocarpio o pulpa del fruto se compone principalmente por células parenquimatosas sin polifenoles; en las células más externas del mesocarpio son evidentes los cloroplastos. En las células más internas se observan los haces vasculares. El desarrollo de C. gloeosporioides se inicia con la metabolización de los polifenoles contenidos en las células epidérmicas y los contenidos en las células de parénquima del exocarpio. No solo existen cambios metabólicos, sino que las paredes celulares quedan impregnadas por el producto resultante que le da un color rojo a las paredes de la célula. Los frutos de aguacate infectados mostraron los síntomas típicos de la 'antracnosis' externos e internos que consisten en la presencia de lesiones necróticas circulares color café oscuro. A los 3 ddi se observó una capa mucilaginosa para la adhesión y degradación de la cutícula (Figura 4-C). El desarrollo de la antracnosis se acompañó de la plasmólisis en 
las células parenquimatosas del mesocarpio, las paredes celulares aún están completas, sin embargo ocurre la deshidratación del citoplasma; por lo tanto, colapsó a los 6 ddi (Figura 4-D) producto de la invasión del hongo. El desarrollo de las estructuras de infección del hongo alcanzó todo el mesocarpio a los 9 ddi observándose el crecimiento del hongo intra en intercelularmente aunque sin necrosamiento (Figura 5-A). A partir de los 12 ddi desarrollaron las hifas hacia el exocarpio para formar los acérvulos (Figura 5-B, C). En esta etapa la cutícula y las células epidérmicas se desorganizan. Finalmente, a los 15 ddi se incrementó la frecuencia de células muertas así como la degradación celular (Figura 5-D) e hiperplasia que, de manera masiva, se observó asociada con el síntoma típico de 'antracnosis' visible externamente en los frutos infectados. Al final de la infección el exocarpio se necrosa con excepción de las esclereidas.

En este estudio, durante las etapas iníciales de la infección el hongo no desarrolló estructuras especializadas para la fijación en la superficie del hospedante, los apresorios. Sin embargo, se detectó una capa mucilaginosa rodeando a las conidias de modo que podría facilitar la adhesión de las conidias a la superficie del fruto de aguacate. Dicha sustancia se ha observado también en los apresorios y en el tubo germinativo de Colletotrichum sp. (ZAMORA-MAGDALENO et al., 2001). La capa mucilaginosa contiene enzimas, cutinasas y esterasas, que degradan la cutícula y permiten que el patógeno se adhiera fácilmente al hospedante (DICKMAN et al., 2003). No todos los aislamientos de C. gloeosporioides forman apresorio sino que pueden penetrar directamente con ayuda del tubo germinativo. También, se ha reportado la síntesis de gloeosporona, terpeno perteneciente al grupo de las lactonas, que funciona como auto-inhibidor de la germinación de conidias y de apresorios de $C$. gloeosporioides (CASCINO et al., 1990; KIM et al., 1999). ZAMORA-MAGDALENO et al. (2001) mencionan que, en las etapas iníciales de infección por antracnosis, no se observa el micelio del hongo invadiendo las células del parénquima del exocarpio y mesocarpio. Resultados semejantes se obtuvieron en este estudio, pues la invasión de las hifas se observó a partir de los 6 ddi, acompañada de la plasmólisis celular. También se observó plasmólisis a los 6 ddi en células íntegras de aguacate pero con el citoplasma contraído. Esto puede ser causado por la penetración de la hifa a las células parenquimatosas como mecanismo de defensa del fruto lo que provocó la contracción del citoplasma. El ciclo de vida del patógeno se completó con la formación de acérvulos
(RODRÍGUEZ-LÓPEZ et al., 2009), mismos que fueron evidentes a partir de los $12 \mathrm{ddi}$. A esa fecha fue evidente la desorganización y degradación celular, aunque no se observó el colapso celular como lo reportaron ZAMORA-MAGDALENO et al. (2001) en aguacate. Sin embargo, la lesión característica causada por C. gloeosporioides y el síntoma de antracnosis si se observó al final de los experimentos, misma que consiste en la producción de manchas circulares color café oscuro en el mesocarpio del fruto. En conclusión, C. gloeosporioides produjo los síntomas de la antracnosis a partir de los diez días después de su inoculación en frutos de aguacatero. Sin embargo, no se detectó la formación de apresorios pero sí se formó la síntesis de una capa mucilaginosa asociada con los tubos germinativos. Además, el proceso infectivo de $C$. gloeosporioides se manifestó a través de la penetración de las hifas intra e intercelularmente y con la producción de acérvulos a partir de los 12 días después de la inoculación. Los síntomas de la antracnosis se asociaron con la degradación de polifenoles, plasmólisis, necrosis y desintegración celular.

E.S. Rodríguez-López agradece el apoyo económico del CONACYT y del Instituto Politécnico Nacional (Beca PIFI) para la realización de sus estudios de Maestría en Ciencias en Biotecnología Genómica en el Centro de Biotecnología Genómica del IPN. Trabajo financiado por el Instituto Politécnico Nacional y por el Programa de Mejoramiento del Profesorado (PROMEP) de la SEP-México. N. Mayek-Pérez y S. Hernández-Delgado son becarios del S. N. I., EDI y COFAA-IPN. 


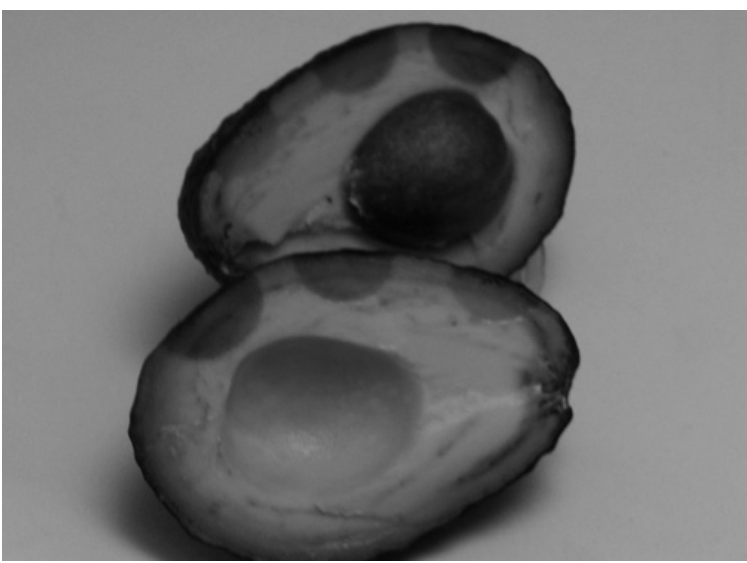

FIGURA 1- Lesiones características causadas por Colletotrichum gloeosporioides en el eje longitudinal de frutos de aguacate 'Hass'.

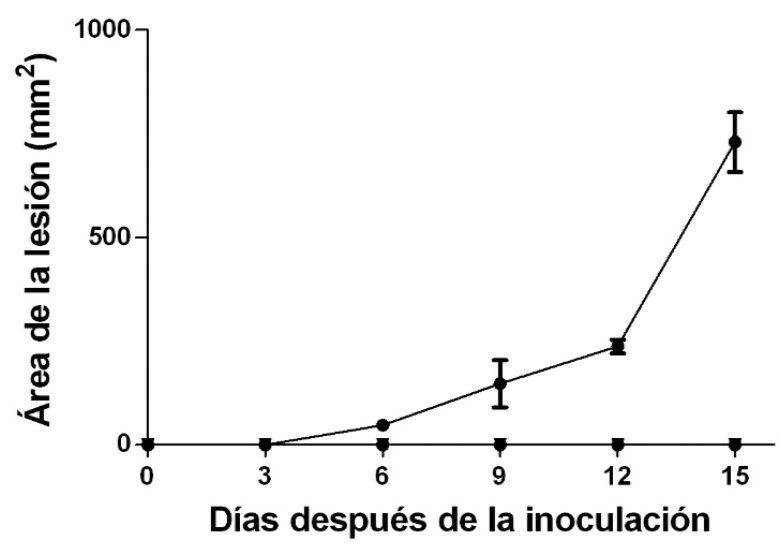

$\rightarrow$ Inoculado con C.gloeosporioides

$\rightarrow \quad$ Testigo (no inoculado)

FIGURA 2 - Crecimiento de la lesión causada por Colletotrichum gloeosporioides en frutos de aguacate 'Hass'. Medias de cuatro repeticiones \pm ES.

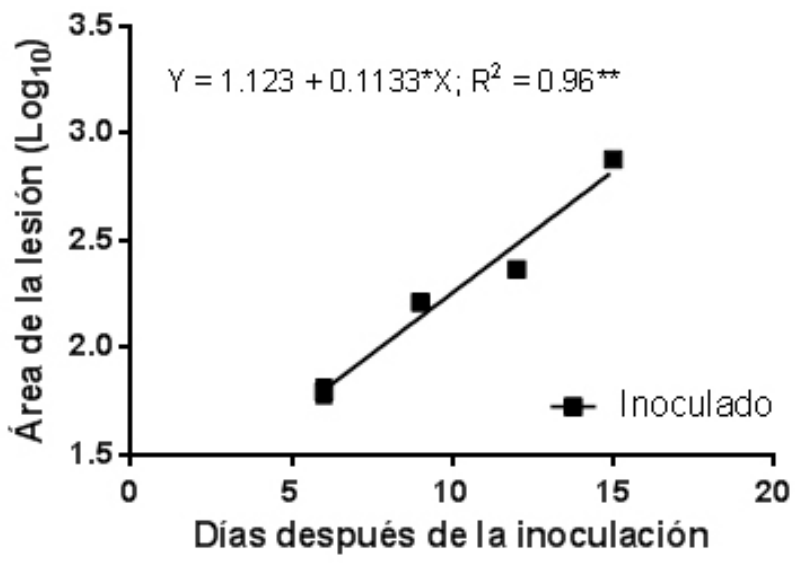

FIGURA 3- Análisis de regresión lineal simple del desarrollo de Colletotrichum gloeosporioides en frutos de aguacate 'Hass'. Los valores son la media de cuatro repeticiones transformados con $\log 10$. 

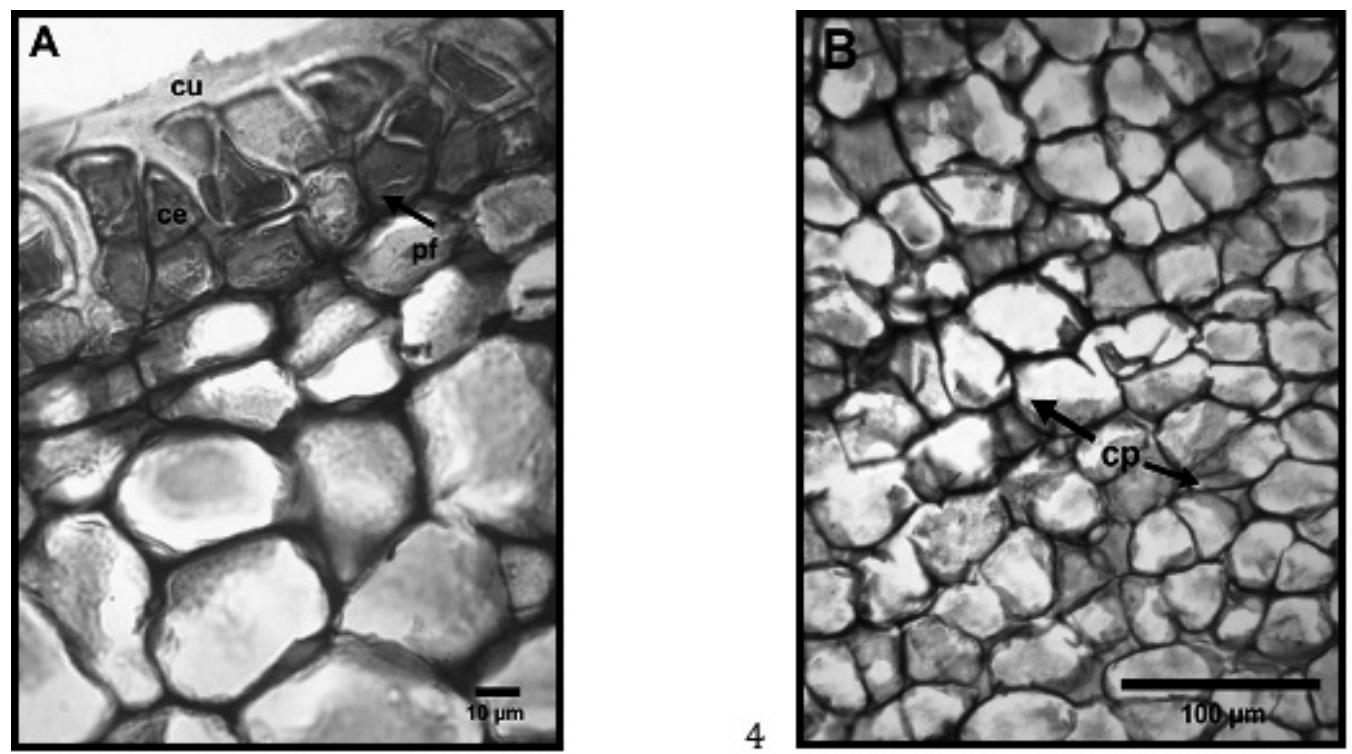

5
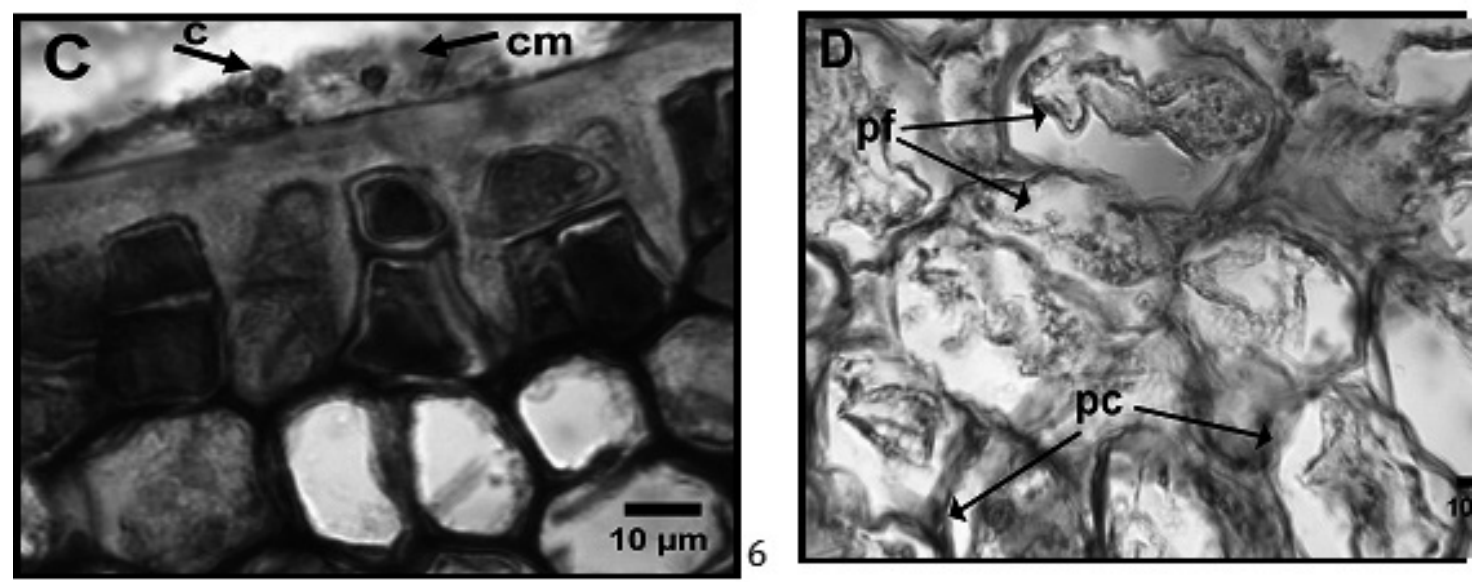

FIGURA 4- Cortes transversales de frutos de aguacate. A) testigo sin infección del hongo; B) testigo sin infección de células parenquimatosas del mesocarpio; C) fruto a los $3 \mathrm{ddi}$, conidias con probable capa mucilaginosa; D) plasmólisis por infección del fruto a los 6 ddi. (cu = cutícula; ce $=$ células epidérmicas; $\mathrm{pf}=$ polifenoles $; \mathrm{c}=$ conidia $; \mathrm{cm}=$ capa mucilaginosa $; \mathrm{cp}=$ células del parénquima; $\mathrm{pp}=$ punta de penetración). 

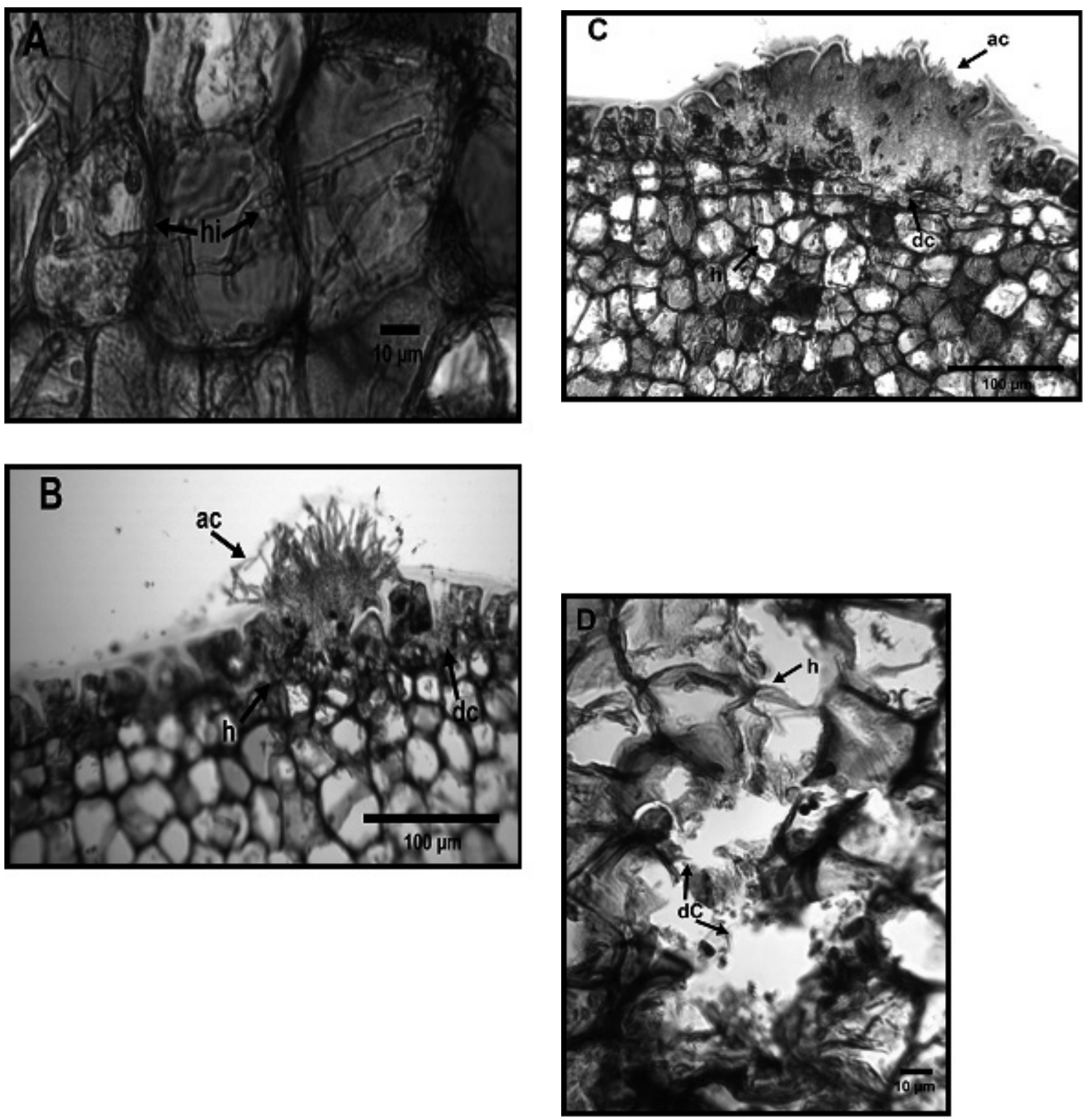

FIGURA 5- Cortes transversales de frutos de aguacate infectados. A) células epidérmicas con hifas intracelulares y extracelulares a los $9 \mathrm{ddi}$; B) formación de acérvulo a partir de los $12 \mathrm{ddi}$; C) acérvulo y desorganización celular en la superficie; D) degradación celular en el mesocarpio a los 15 ddi. (hi = hifa intracelular; he = hifa extracelular; $a c=$ acérvulo; $h=$ hifas; $d c=$ desorganización celular; $\mathrm{dC}=$ degradación celular). 


\section{REFERÊNCIAS}

BENO, D.B.; PRUSKY, D. Early events during quiescent infection development by Colletotrichum gloeosporioides in unripe avocado fruits. Phytopathology, Saint Paul, v.90, n.5, p.553-559, 2000.

CANO, J.; GUARRO, J.; GENÉ, J. Molecular and morphological identification of Colletotrichum species of clinical interest. Journal of Clinical Microbiology, Washington, v.42, n.6, p.2.450-2.454, 2004.

CASCINO, J.J.; HARRIS, R.F.; SMITH, C.S.; ANDREWS, J.H. Spore yield and microcycle conidiation of Colletotrichum gloeosporioides in liquid culture. Applied and Environmental Microbiology, Washington, v.56, n. 8, p.2.3032.310, 1990 .

DICKMAN, M.B.; HA, Y.S.; ADAMS, B.; HUANG, C. A protein kinase from Colletotrichum trifolii is induced by plant cutin and is required for appressorium formation. Molecular Plant-Microbe Interactions, Saint Paul, v.16, n.5, p.411-421, 2003.

FREEMAN, S.; KATAN, T.; SHABI, E. Characterization of Colletotricum gloeosporioides isolates from avocado and almond fruits with molecular and pathogenicity test. Applied and Enviromental Microbiology, Washington, v.62, n.3, p.1.014-1.020, 1996.

FREEMAN, S.; MINZ, D.; JURKEVITCH, E.; MAYMON, M.; SHABI, E. Molecular analyses of Colletotrichum species from almond and other fruits. Phytopathology, Saint Paul, v.90, n.6, p.608-614, 2000.

KIM, K.D.; OH, B.J.; YANG, J. Differential interactions of a Colletotrichum gloeosporioides isolate with green and red pepper fruits. Phytoparasitica, Heidelberg, v.27, n.1, p.1-10, 1999.

PRUSKY, D.; FREEMAN, S.; DICKMAN, M. Colletotrichum. Host specificity, pathology, and host-pathogen interaction. . St. Paul: American Phytopathological Society Press, 2000. 393 p.

PRUSKY, D.; McEVOY, J.; LEVERENTZ, R.; CONWAY, W. Local modulation of host $\mathrm{pH}$ by Colletotrichum species as a mechanism to increase virulence. Phytopathology, Saint Paul, v.91, n.11, p.1105-1113, 2001.
RAMÍREZ-GUZMÁN, M.E.; LÓPEZ-TIRADO, Q. Métodos estadísticos no paramétricos. Chapingo: Universidad Autónoma Chapingo, 1993. 223 p.

ROCA, M.M.G.; ONGARELLI, M.G.; DAVIDE, L.C.; MENDES, C.M.C. Ultrastructural aspects in perithecia hyphae septal pores of Glomerella cingulata f. sp. Brazilian Journal of Microbiology, Sao Paulo, v.31, n.3, p.223-225, 2000.

RODRÍGUEZ-LÓPEZ, E.S.; GONZÁLEZPRIETO, J.M.; MAYEK-PÉREZ, N. La infección de Colletotrichum gloeosporioides (Penz.) Penz.y Sacc. en aguacatero (Persea americana Mill.): Aspectos bioquímicos y genéticos. Revista Mexicana de Fitopatología, Ciudad Obregón, v.27, n.1, p.53-63, 2009.

TALHINHAS, P.; SREENIVASAPRASAD, S.; NEVES, J.; OLIVERA, H. Molecular and phenotypic analyses reveal association of diverse Colletotrichum acutatum groups and a low level of $C$. gloeosporioides with olive anthracnose. Applied and Enviromental Microbiology, Washington, v.71, n.6, p.2.987-2.998, 2005.

VILLANUEVA-ARCE，R.; CÁRDENASSORIANO, E.; HERNÁNDEZ-ANGUIANO, A.M.; MORA-AGUILERA, A.; TÉLIZ, O.D. Patogénesis de la antracnosis (Colletotrichum fragariae) en frutos de chirimoya. Agrociencia, Montecillo, v.40, n.6, p.773-782, 2006.

WHITELAW, W.M.A.; CURTIS, S.J.; HUANG, R.; STEEL, C.C.; BLANDCHARD, C.L.; ROFFEY, P.E. Phylogenetic relationships and pathogenicity of Colletotrichum acutatum isolates from grape in subtropical Australia. Plant Pathology, Chichester, v.56, n.3, p.448-463, 2007.

XIAO, C.L.; MACKENZIE, S.J.; LEGARD, D.E. Genetic and pathogenic analyses of Colletotrichum gloeosporioides isolates from strawberry and noncultivated host. Phytopathology, Saint Paul, v.94, n.5, p.446-453, 2004.

ZAMORA-MAGDALENO, T.; CÁRDENASSORIANO, E.; CAJUSTE-BONTEMPS, J.F.; COLINAS-LEÓN, M. T. Anatomía del daño por rozamiento y por Colletotrichum gloeosporioides Penz. en fruto de aguacate 'Hass'. Agrociencia, Montecillo, v.35, n.2, p.237-244, 2001. 